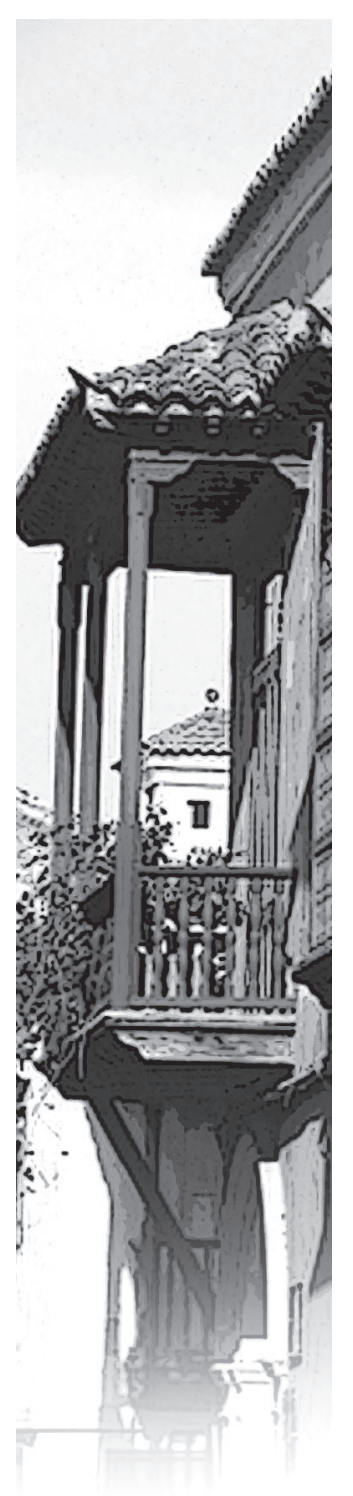

\title{
SISTEMAS DE RIESGOS LABORALES EN AMÉRICA LATINA Y OTROS PAÍSES
}

\section{BEDOYA-MARRUGO ELÍAS ALBERTO}

Sistema de riesgos laborales en América Latina y otros países es un texto compilatorio de legislaciones sobre seguridad social de los sistemas de riesgos laborales de 18 países distintos, incluyendo Colombia. Junto a esta compilación, se presentan los conceptos relacionados con accidentes de trabajo y enfermedad laboral para cada uno de los países estudiados. El texto permite revisar de forma detallada y esquemática la manera en la que cada país mencionado aborda la temática de los sistemas de seguridad social, teniendo en cuenta sus características y principios particulares.

\section{SISTEMAS DE RIESGOS} LABORALES

ELIAS ALBERTO BEDOYA MARRUGO

Del mismo modo, se establece una conexión entre las definiciones de los diferentes sistemas de riesgos laborales junto al análisis comparativo con el concepto colombiano de accidentes de trabajo y enfermedad laboral. Este texto se dirige a quienes estudian la seguridad y la salud del trabajo, a docentes de estas asignaturas, a legisladores y a aquellos que desean conocer el manejo de la normatividad en seguridad social y riesgos laborales en países de varios continentes.

Este documento es, sin duda, un excelente texto de consulta académica e investigativa de fácil lectura y comprensión. El autor del texto es Administrador de Servicio de Salud, Especialista en Salud Ocupacional, Gestión de Calidad y Auditoría en Salud, Magíster en Administración, Especialista en Gestión Integral de la Calidad, Seguridad y Medio Ambiente. Elías Alberto Bedoya es docente catedrático en el programa de Enfermería de la Universidad de Cartagena. 